\title{
Thoracic radiation-induced pleural effusion and risk factors in patients with lung cancer
}

\author{
Jing Zhao ${ }^{1,2, *}$, Regina M. Day ${ }^{3, *}$, Jian-Yue Jinn ${ }^{2,4}$, Leslie Quint ${ }^{5}$, Hadyn Williams ${ }^{6}$, \\ Catherine Ferguson², Li Yan², Maurice King ${ }^{2}$, Ahmad Albsheer ${ }^{2}$, Martha Matuszak ${ }^{7}$ \\ and Feng-Ming (Spring) Kong ${ }^{2,8}$ \\ ${ }^{1}$ Department of Oncology, Tongji Hospital, Tongji Medial College, Huazhong University of Science and Technology, Wuhan, \\ Hubei, China \\ ${ }^{2}$ Department of Radiation Oncology, Medical College of Georgia, Augusta University, Augusta, GA, USA \\ ${ }^{3}$ Department of Pharmacology, Uniformed Services University of the Health Sciences, Bethesda, MD, USA \\ ${ }^{4}$ Department of Radiation Oncology, Radiation Physics, Indiana University School of Medicine, Indianapolis, IN, USA \\ ${ }^{5}$ Department of Radiology, University of Michigan, Ann Arbor, MI, USA \\ ${ }^{6}$ Department of Radiology, Medical College of Georgia, Augusta University, Augusta, GA, USA \\ ${ }^{7}$ Department of Radiation Oncology, University of Michigan, Ann Arbor, MI, USA \\ ${ }^{8}$ Department of Radiation Oncology, IU Simon Cancer Center, Indiana University School of Medicine, Indianapolis, IN, USA \\ "These authors contributed equally to this work
}

Correspondence to: Feng-Ming (Spring) Kong, email: fskong@iupui.edu

Keywords: lung cancer, thoracic radiotherapy, radiation induced pleural effusion, risk factors, overall survival

Received: May 07, $2017 \quad$ Accepted: June 08, $2017 \quad$ Published: June 29, 2017

Copyright: Zhao et al. This is an open-access article distributed under the terms of the Creative Commons Attribution License 3.0 (CC BY 3.0), which permits unrestricted use, distribution, and reproduction in any medium, provided the original author and source are credited.

\section{ABSTRACT}

The risk factors and potential practice implications of radiation-induced pleural effusion (RIPE) are undefined. This study examined lung cancer patients treated with thoracic radiation therapy (TRT) having follow-up computed tomography (CT) or 18F-fluorodeoxyglucose (FDG) positron emission tomography (PET)/CT. Increased volumes of pleural effusion after TRT without evidence of tumor progression was considered RIPE. Parameters of lung dose-volume histogram including percent volumes irradiated with 5-55 Gy (V5-V55) and mean lung dose (MLD) were analyzed by receiver operating characteristic analysis. Clinical and treatment-related risk factors were detected by univariate and multivariate analyses. 175 out of 806 patients receiving TRT with post-treatment imaging were included. 51 patients

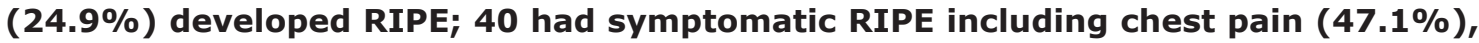
cough $(23.5 \%)$ and dyspnea (35.3\%). Female (OR $=0.380,95 \%$ CI: $0.156-0.926$, $p=0.033)$ and Caucasian race $(O R=3.519,95 \% C I: 1.327-9.336, p=0.011)$ were significantly associated with lower risk of RIPE. Stage and concurrent chemotherapy had borderline significance $(O R=1.665, p=0.069$ and $O R=2.580, p=0.080$, respectively) for RIPE. Patients with RIPE had significantly higher whole lung V5-V40, V50 and MLD. V5 remained as a significant predictive factor for RIPE and symptomatic RIPE ( $p=0.007$ and 0.022$)$ after adjusting for race, gender and histology. To include, the incidence of RIPE is notable. Whole lung V5 appeared to be the most significant independent risk factor for symptomatic RIPE.

\section{INTRODUCTION}

Thoracic radiation therapy (TRT) is an important component of multi-modality treatment for breast cancer, esophageal cancer, and lung cancer including small cell and non-small cell lung cancer (NSCLC) [1, 2]. TRT can improve survival rates for patients with inoperable stage I or II NSCLC [2-4] and limited stage small cell lung cancer [5]. TRT is a mainstay treatment in combined multi-modalities of surgery and chemotherapy for breast cancer, esophagus cancer, and NSCLC [6-9]. Combination of targeted therapies including immunotherapies with 
radiation may also significantly improve patient survival in NSCLC [10, 11].

Pulmonary toxicity is a known concern for the use of TRT [12-20]. The total dose of radiation, fraction sizes, volume of lung exposure, and the concurrence of chemotherapeutic treatments have been shown to be factors for toxicity to the lung [13, 21, 22]. Radiationinduced lung injury includes bronchial stenosis, lung edema, pleural effusions, fibrosis, and pneumonitis [23]. As a late effect after TRT, pleural effusion is often induced by inflammation and immune cells such as macrophages and $\mathrm{CD}^{+} \mathrm{T}$ cells. Radiation-induced lung toxicity (pneumonitis and fibrosis) occurs in $10 \%$ to $30 \%$ of patients following TRT $[24,25]$. Interstitial pulmonary effects are observed in patients undergoing radiotherapy for bone marrow transplantation [26-29]. Previous partialvolume irradiation parameters were derived from literature reviews and the experience of radiation oncologists $[20,30]$. The tolerance doses (TD) for less than $5 \%$ risk of lung injury within 5 years of radiation exposure for $1 / 3$, $2 / 3$ or $3 / 3$ of lung volume were empirically considered to be 45,30 , and $17.5 \mathrm{~Gy}$, respectively [20]. Recently, dosimetric factors such as V20 and mean lung dose have been developed to assess the risk of symptomatic radiation-induced lung toxicity (RILT), primarily the development of pneumonitis and fibrosis [22, 31, 32].

To date, a majority of studies investigating risk for lung toxicity in response to radiation have focused primarily on development of pneumonitis and fibrosis [30]. Pleural effusions are frequent manifestations of a variety of systemic and local diseases and are readily and frequently detected on chest radiographs. The appearance of pleural fluid in vivo depends on chest wall and lung elasticity and on pressure relationships. Pleural effusion can also develop after radiation damage to the lungs and is considered to be one of the most common late toxicities after TRT [33-35]. Although pleural effusions have been recognized as an adverse effect of radiation exposure for over 50 years, the frequency and risk factors have not been systematically studied during the last two decades [36]. We investigated the rate of thoracic radiation-induced pleural effusion (RIPE) and its risk factors for RIPE in patients with lung cancer.

\section{MATERIALS AND METHODS}

\section{Patients}

\section{Patient eligibility}

Lung cancer patients treated with TRT between January 2004 and Dec 2014 from two centers (Augusta University and University of Michigan) were reviewed retrospectively on the basis of: pathologically confirmed non-small cell lung cancer, treatment of thoracic RT \pm chemotherapy, available computed tomography (CT) scan or PET/CT for treatment planning and dosimetric analysis, 6-month clinical follow-up after RT, with no evidence of local disease progression and initial Eastern Cooperative Oncology Group performance status $(\mathrm{ECOG}) \leq 2$. Clinical staging was classified according to the American Joint Commission on Cancer staging system, 7th edition [37]. This research was part of an Institutional Review Board approved retrospective study.

\section{Treatment planning and follow-up}

Patients were treated with conventionally fractionated (1.8 or $2.0 \mathrm{~Gy} /$ fraction) using 6-, 10-, or 18MV photons. Most patients were treated with $\geq 60$ Gy in 30 fractions over 6 weeks. All patients underwent threedimensional conformal radiation therapy (3D-CRT) with a CT simulation with a slide thickness of 3.0-5.0 mm. The dose-volume histograms (DVH) parameters analyzed included mean total lung dose (MLD), and volumes of total lung receiving 5 to 55 Gy for each 5 Gy (V5, V10, V15, V20, V25, V30, V35, V40, V45, V50, V55, respectively). Total lung excluding the main bronchus and gross tumor volume was delineated for lung dosimetry computation.

Chemotherapy regimens were mainly based on carboplatin with paclitaxel, or cisplatin with etoposide. Patients were followed per standard of practice. At followup, a history, physical examination, and CT of chest or PET-CT were obtained. Chest CT scans and PET/CT were reviewed to evaluate RIPE. Adverse events were graded retrospectively according to the National Cancer Institute-Common Toxicity Criteria Version, version 4.0. Symptomatic effusion was defined as effusion $\geq$ grade 2 . The following clinical factors were investigated in relation to RIPE: age, gender, race, ECOG score, histology, clinical stage, smoking status, chemotherapy, and radiation dose.

\section{Evaluation of pleural effusion}

The diagnosis of pleural effusion was independently assessed by one physician, and was spot checked by another physician. Several previous studies reported models based on simple measurement from the chest radiographs to estimate the volume of pleural effusions [38-41]. Patients with fluid loculation were not excluded. We selected the model from Hazlinger, et al. [40], who reported the dimension of effusion depth as the best planar measurement which was significantly correlated with the actual PE. The model described by Hazlinger, et al., estimates the PE volumes from $\mathrm{CT}$ scans using the formula: the volume of $\mathrm{PE}=0.365 \times \mathrm{b}^{3}-4.529 \times \mathrm{b}^{2}+$ $159.723 \times b-88.377$, where $b$ was the depth measured perpendicularly to the parietal pleura on transversal CT scan where the greatest depth was found by scrolling through all the images [40]. An example of measurement is shown in Figure 1. New pleural effusion or increased 
volume of PE after TRT without evidence of tumor progression was considered to be RIPE. To determine the most relevant dose-volume parameter, a receiver operator characteristic (ROC) curve was constructed. The Youden Index was used as the optimal cutoff from the curve, which is defined as sensitivity + specificity- 1 .

\section{Statistical analysis}

Time to RIPE was calculated from the last day of TRT to the date at which pleural effusion was observed on the follow-up scan. Patients without pleural effusion (PE) were censored at the last follow-up or death. The overall survival (OS) was defined as the interval between the date of treatment initiation and the date of death, or time of the last follow-up for patients still alive, which was estimated using the Kaplan-Meier method. The logistic regression model was used for multivariate analysis. All analyses were two-sided and differences were considered statistically significant at $p<0.05$. Statistical analyses were performed employing SPSS, version 19.0 (SPSS Inc, Chicago IL).

\section{RESULTS}

\section{Patient characteristics}

Of 806 patients treated with TRT between 2004 and 2013, 175 with post-treatment imaging available in our electronic medical system and with no evidence of thoracic disease progression were included in this study. The characteristics of the eligible patients were summarized in Table 1. The median OS was 20.5 (range, 6.37-113.2) months. Concurrent chemotherapy was administered to 119 patients.

\section{Incidence of radiation induced pleural effusion}

RIPE of any grade developed in 51 (29.1\%) patients, in which 39 patients had newly developed PE after TRT without disease progression and the remaining 12 patients had PE increases after TRT. The median (range) change of PE depth was $13.6(2-90.6) \mathrm{mm}$, and the median (range) change of estimate PE volume was $2164.3(215.9-248,649) \mathrm{ml}$. The median (range) RIPE interval from end of TRT was 3.7 (0.6-18.0) months. Forty patients developed symptomatic RIPE; 24 of these patients $(60.0 \%)$ presented with chest pain; 12 (30.0\%) suffered from cough; and 18 (45.0\%) had shortness of breath or dyspnea. The actuarial incidence of RIPE at 1 and 2 years for those 51 patients was $88.8 \%$ and $11.2 \%$, respectively. The RIPE rates of the two institutions in all patients were $22.6 \%$ and $38.6 \%$ with a borderline significance in difference $(p=0.055)$.

\section{Risk factor analysis for patient characteristics}

The logistic regression analysis of risk factors for RIPE is shown in Table 2. In all 175 patients, only gender and race were significantly correlated with the occurrence of RIPE: Female (OR $=0.380,95 \%$ CI: $0.156-0.926, p=0.033$ )

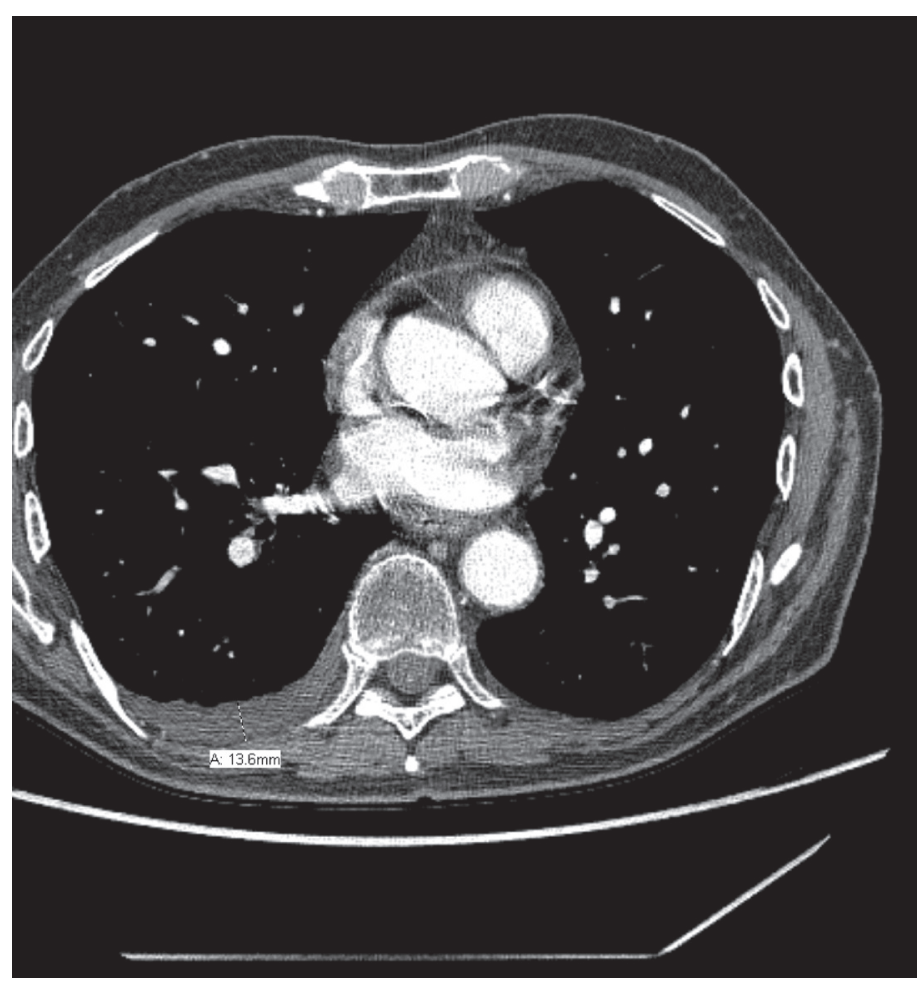

Figure 1: Example measurement for radiation induced pleural effusion. 
Table 1: Patient characteristics

\begin{tabular}{|c|c|c|}
\hline Characteristics & Subgroup & No. Patients (\%) \\
\hline \multirow[t]{2}{*}{ Age (years) } & $\leq 65$ & $98(56.0)$ \\
\hline & $\geq 65$ & $77(44.0)$ \\
\hline \multirow[t]{2}{*}{ Gender } & Male & $125(71.4)$ \\
\hline & Female & $50(28.6)$ \\
\hline \multirow[t]{2}{*}{ Race } & Caucasian & $142(81.1)$ \\
\hline & African American & $33(18.9)$ \\
\hline \multirow[t]{3}{*}{ Histology } & Squamous cell carcinoma & $47(26.9)$ \\
\hline & Adenocarcinoma & $57(32.6)$ \\
\hline & Others & $71(40.5)$ \\
\hline \multirow[t]{3}{*}{ Stage } & I & $28(16.0)$ \\
\hline & II & $32(18.3)$ \\
\hline & III & $115(65.7)$ \\
\hline \multirow[t]{3}{*}{ Smoking status } & Non-smoker & $16(9.1)$ \\
\hline & Former smoker & $88(50.3)$ \\
\hline & Current smoker & $71(40.6)$ \\
\hline \multirow[t]{2}{*}{ Concurrent chemotherapy } & Yes & $119(68.0)$ \\
\hline & No & $56(32.0)$ \\
\hline \multirow[t]{2}{*}{ Radiation dose (Gy) } & $\geq 60$ & $123(70.3)$ \\
\hline & $<60$ & $52(29.7)$ \\
\hline
\end{tabular}

Baseline demographic and clinical characteristics of the patients at diagnosis.

Table 2: Multivariate analysis of patient characteristics as risk factors

\begin{tabular}{cccc}
\hline Characteristics & OR & $\mathbf{9 5 \%} \mathbf{C I}$ & $\boldsymbol{P}$ \\
\hline Age (years) & 1.178 & $0.528-2.629$ & 0.690 \\
Gender & 0.380 & $0.156-0.926$ & 0.033 \\
Race & 3.519 & $1.327-9.336$ & 0.011 \\
Histology & 0.705 & $0.447-1.112$ & 0.132 \\
Stage & 1.665 & $0.961-2.883$ & 0.069 \\
Smoking status & 0.905 & $0.493-1.664$ & 0.749 \\
Concurrent chemotherapy & 2.508 & $0.897-7.014$ & 0.080 \\
Radiation dose & 0.830 & $0.298-2.314$ & 0.721 \\
\hline
\end{tabular}

and Caucasian race $(\mathrm{OR}=3.519,95 \% \mathrm{CI}: 1.327-9.336$, $p=0.011$ ) had lower risk of RIPE. Stage and concurrent chemotherapy were correlated with the occurrence of RIPE with a borderline significance $(\mathrm{OR}=1.665, p=0.069$ for advanced stage and $\mathrm{OR}=2.580, p=0.080$, for receiving concurrent chemotherapy). 


\section{Lung volume exposure correlation with development of RIPE}

The ROC curve analysis results are shown in Figures 2 and 3, and Tables 3 and 4. The whole lung V5, V10, V15, V20, V25, V30, V35, V40, V50 and MLD were significantly higher in patients with RIPE than in those without RIPE $(p=0.007,0.011,0.028,0.047$, $0.038,0.019,0.013,0.034,0.040$ and 0.034$)$, however only V5 remained as a significant predictive factor for symptomatic RIPE ( $p=0.022)$ after adjusting for race, age and histology, with the largest area under the ROC curve $(\mathrm{AUC}=0.767)$. For patients with symptomatic RIPE, using a cutoff of $41.5 \%$ for V5, the sensitivity and specificity were $100 \%$ and $38.1 \%$, respectively.

\section{Correlation of RIPE with overall survival}

In total, 109 patients died during a median follow up of 19.5 months. RIPE was not significantly correlated with the overall survival (Figure 3 ). The median (95\% CI) overall survival rates for patients with or without RIPE were 22.0 (17.8-26.2) and 27.0 (20.4-33.5) months, respectively $(p=0.773)$ (Figure 4$)$.

\section{DISCUSSION}

This study demonstrated that RIPE occurred in $29.1 \%$ of patients treated with TRT. In $80 \%$ of patients with RIPE, there was an association with significant symptoms, such as chest pain and shortness of breath. Lung dosimetric factors were significantly greater for patients with RIPE, but only V5 was statistically significant for symptomatic RIPE in this series. Interestingly, Caucasian race and squamous cell tumor histology were each associated with a lower risk for RIPE.

Dose-volume parameters that predict the occurrence of RIPE include the dose of radiation and the volume of the lung exposed to radiation. Our study indicated that although patients with RIPE had exposures from V5V55, only V5 was a significant risk factor for RIPE. According to the latest National Comprehensive Cancer Network guidelines, the limit of lung volume receiving more than 20 Gy and 5 Gy (V20 and V5) were 35\% and $65 \%$, respectively [35]. The data used to generate these guidelines were largely obtained from studies of symptomatic radiation pneumonitis, and did not take into consideration symptomatic RIPE as a late side effect. In our current study, we found that $<41.5 \%$ could be a threshold to avoid a high risk of RIPE, suggesting that potential benefit of better treatment plans with more stringent limit of V5 to decrease the risk of late symptomatic RIPE. Future studies should validate our findings by defining pleural surface and generate the pleural dosimetry as one of organs at risk for RT planning in the clinic and consider RIPE in animal studies.

Our current study found that a significant number of patients with pleural effusions also had chest pain, dry

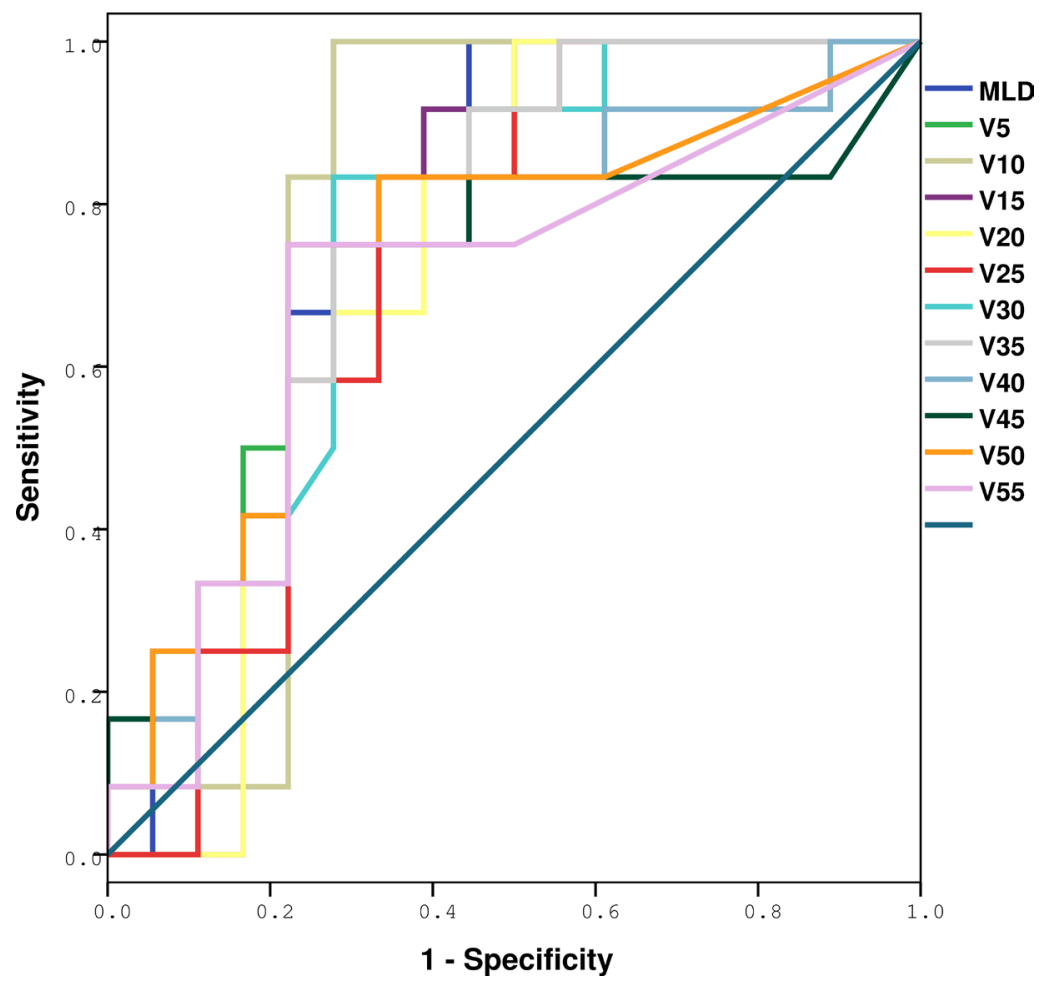

Figure 2: ROC analysis of various dosimetric factors with RIPE. Definition of abbreviations: ROC = receiver operating characteristic curves; RIPE = radiation-induced pleural effusion, $\mathrm{Vx}=$ Volume of total lung received more than $\mathrm{x}$ Gy. 
Table 3: Dose-volume histogram and mean lung dose prediction of any radiation-induced pleural effusions by ROC and AUC

\begin{tabular}{ccccc}
\hline Variables & AUC from ROC & SE & $\mathbf{9 5 \%}$ CI & $p$ \\
\hline V5 & 0.796 & 0.086 & $0.627-0.966$ & 0.007 \\
V10 & 0.778 & 0.094 & $0.593-0.963$ & 0.011 \\
V15 & 0.741 & 0.094 & $0.557-0.924$ & 0.028 \\
V20 & 0.718 & 0.095 & $0.531-0.904$ & 0.047 \\
V25 & 0.727 & 0.093 & $0.544-0.910$ & 0.038 \\
V30 & 0.757 & 0.089 & $0.583-0.931$ & 0.019 \\
V35 & 0.773 & 0.085 & $0.607-0.940$ & 0.013 \\
V40 & 0.731 & 0.097 & $0.542-0.921$ & 0.034 \\
V45 & 0.704 & 0.106 & $0.495-0.912$ & 0.063 \\
V50 & 0.731 & 0.098 & $0.539-0.924$ & 0.034 \\
V55 & 0.692 & 0.104 & $0.489-0.895$ & 0.079 \\
MLD & 0.773 & 0.086 & $0.604-0.942$ & 0.013 \\
\hline
\end{tabular}

Definition of abbreviations: $\mathrm{ROC}=$ receiver operating characteristic curves; $\mathrm{AUC}=$ area under the curve; $\mathrm{SE}=$ standard error of the mean; $\mathrm{CI}=$ confidence interval.

Table 4: Dose-volume histogram and mean lung dose prediction of symptomatic radiation-induced pleural effusions by ROC and AUC

\begin{tabular}{ccccc}
\hline Variables & AUC from ROC & SE & $\mathbf{9 5 \%}$ CI & $\boldsymbol{p}$ \\
\hline V5 & 0.767 & 0.085 & $0.601-0.934$ & 0.022 \\
V10 & 0.714 & 0.094 & $0.530-0.899$ & 0.067 \\
V15 & 0.635 & 0.099 & $0.441-0.828$ & 0.248 \\
V20 & 0.614 & 0.100 & $0.417-0.810$ & 0.331 \\
V25 & 0.619 & 0.101 & $0.422-0.817$ & 0.309 \\
V30 & 0.640 & 0.100 & $0.444-0.837$ & 0.230 \\
V35 & 0.677 & 0.097 & $0.487-0.867$ & 0.129 \\
V40 & 0.624 & 0.111 & $0.407-0.842$ & 0.288 \\
V45 & 0.593 & 0.123 & $0.351-0.834$ & 0.428 \\
V50 & 0.635 & 0.114 & $0.411-0.858$ & 0.248 \\
V55 & 0.606 & 0.118 & $0.375-0.837$ & 0.365 \\
MLD & 0.688 & 0.095 & $0.510-0.874$ & 0.108 \\
\hline
\end{tabular}

Definition of abbreviations: $\mathrm{ROC}=$ receiver operating characteristic curves; AUC $=$ area under the curve; $\mathrm{SE}=$ standard error of the mean; $\mathrm{CI}=$ confidence interval.

cough, and dyspnea, in agreement with previous findings [42]. The management of pleural effusions depends upon the underlying etiology [42]. When associated with disease states, pleural effusions, both benign effusions and cancer-associated, are correlated with high mortality $[43,44]$. Pleural effusions are a significant risk factor for the treatment of thoracic cancers [45], and the presence of pleural effusions with lung cancer can preclude curative surgery [45].

This etiology of pleural effusions following radiation treatment of thoracic cancers remained to be studied. The presence of pleural effusions in malignancy often correlate 


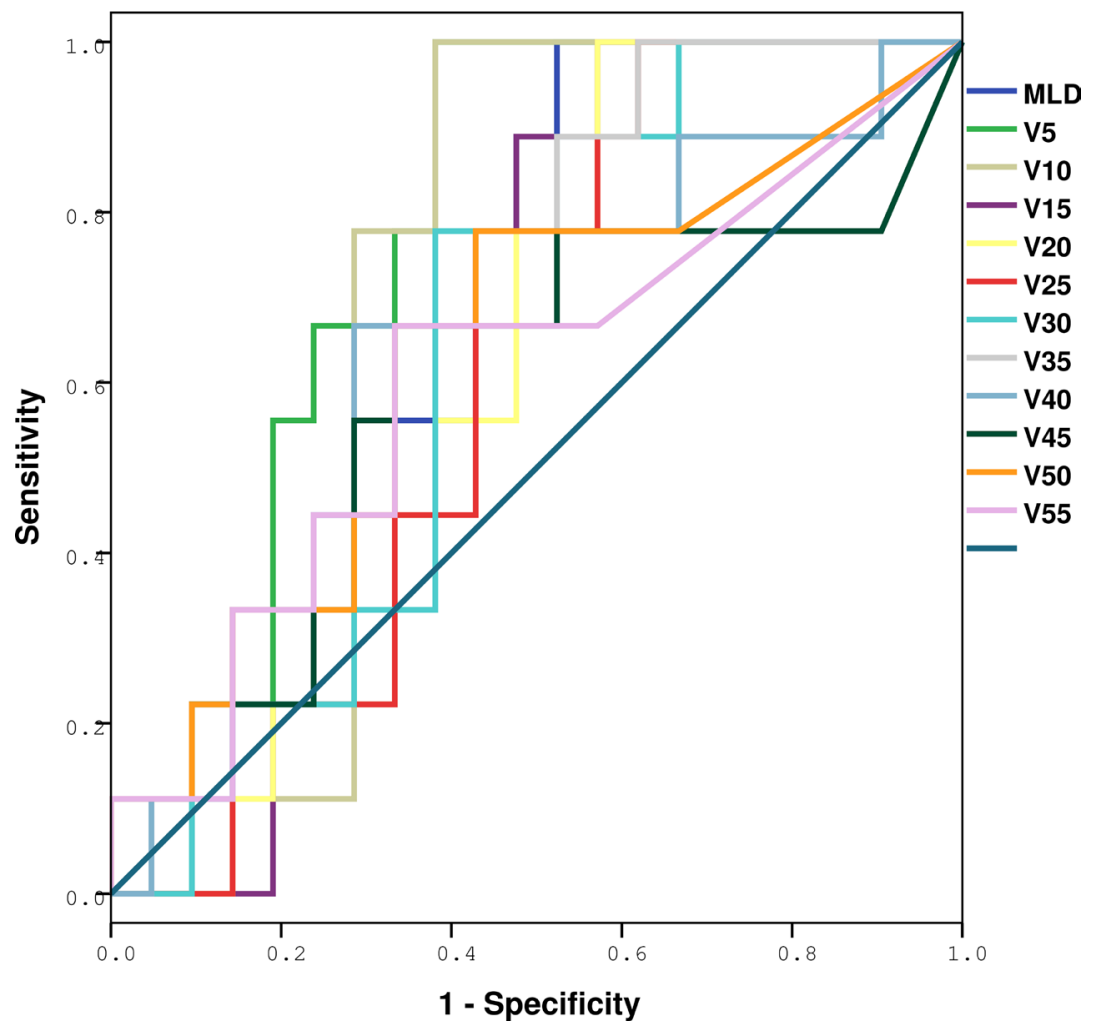

Figure 3: ROC analysis of various dosimetric factors with symptomatic RIPE. Definition of abbreviations: ROC = receiver operating characteristic curves; RIPE = radiation-induced pleural effusion.

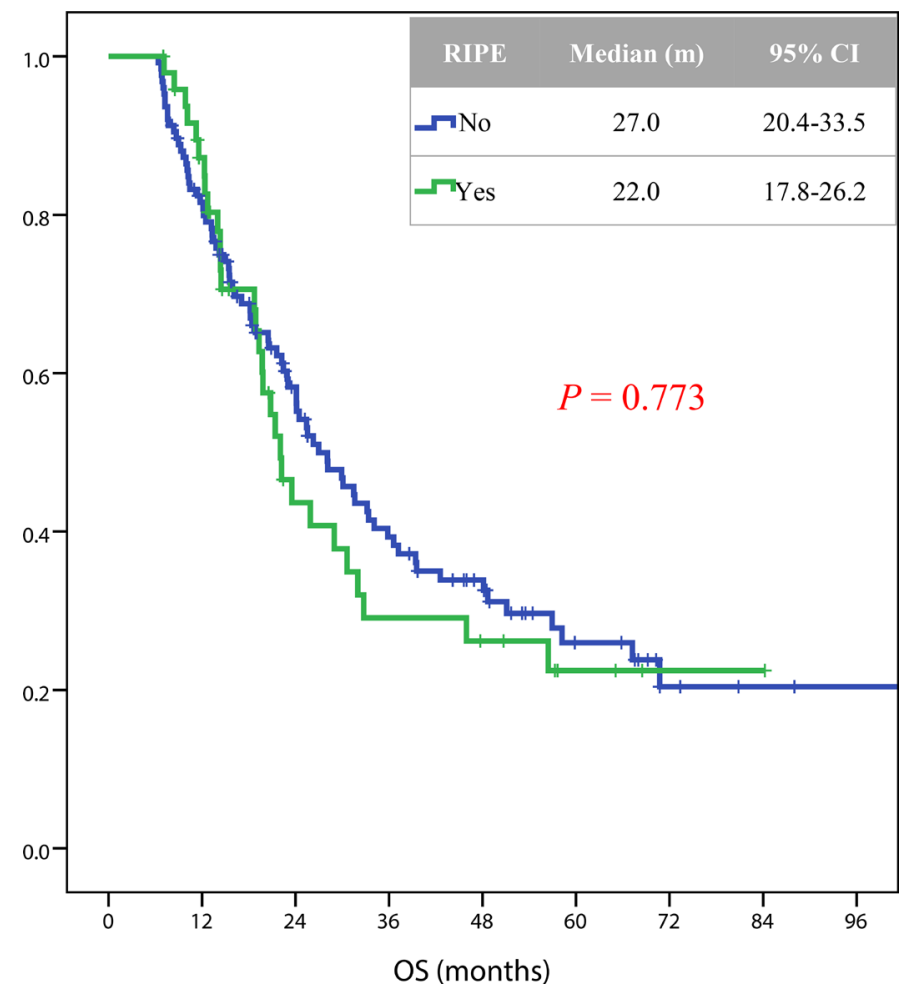

Figure 4: Kaplan-Meier estimates of OS in 205 patients with or without RIPE after radiotherapy. Definition of abbreviations: $\mathrm{OS}=$ overall survival; RIPE = radiation-induced pleural effusion. 
with changes in the disease course and predict changes in responses to cancer therapies [44, 45]. However, both non-inflammatory and inflammatory reactions to radiation can cause increased fluid in the pleural cavity $[42,46]$. Normally, the pleural surface is surrounded by $\sim 15 \mathrm{ml}$ of acellular, clear fluid that acts as a lubricant for the thoracic cavity. Post-RT pleural effusion could also be from benign pleural causes such as cardiac, kidney or liver failure, infections (such as tuberculosis, pneumonia, lung infarcts, lung abscess, and bronchiectasis), systemic disorders (such as rheumatoid arthritis, systemic lupus erythematosus, uremia, or systemic infections), trauma, or radiation therapy.

The biology or cytopathology of pleural effusions following ionizing radiotherapy has also not been systematically studied [47]. One study examined specimens from 55 irradiated patients with pleural effusions and identified bizarre cells, but no other distinctive cytologic changes [47]. Increased secretion into the pleural space is thought to involve a wide variety of cells, including mesothelial, endothelial, myeloid, and lymph cells [44]; in the case of malignant pleural effusions (MPEs), tumor cells are also thought to contribute significantly to secretions [44]. Tumor volumes and tumor metabolic activities, as well as the unique tumor secretome have been demonstrated to affect MPEs, which are a common complication of advanced malignancy [45]. A variety of biochemical markers have been identified in MPEs, including $\mathrm{pH}$, lactate dehydrogenase, neutrophil-tolymphocyte ratio, and the protein surviving, and attempts have been made to correlate these factors with patient prognosis [45]. Reasons of MPE cannot explain RIPE as we only elected those without tumor progression for radiation induced toxicity.

Murine model studies of the effects of thoracic irradiation have demonstrated that pleural effusions occur in a number of rodent models including rats and some strains of mice $[35,48]$. Whole thorax irradiation was also demonstrated to induce hypoxic respiratory failure, cardiac injury, and pleural effusions in Wistar rats [35]. However, recent recommendations have been to select murine strains that do not exhibit pleural effusions in studies of radiationinduced lung injury [35, 48]. In light of our current finding, the study of murine models that do develop RIPE is essential to the understanding of the complexity of radiation-induced injuries to the thoracic tissues in patients. The use of murine models with RIPE would additionally aid in the understanding of the mechanism(s) of pleural effusion in response to ionizing radiation as well as the identification of cytologic alterations that occur. Considering the relative high rate of RIPE and its clinical significance, future studies are needed to understand the mechanism in both animal models and patients.

\section{Abbreviations}

TRT: Thoracic radiation therapy; NSCLC: nonsmall cell lung cancer; RILT: radiation-induced lung toxicity; RIPE: radiation-induced pleural effusion; ECOG: Eastern Cooperative Oncology Group performance status; 3D-CRT: three-dimensional conformal radiation therapy; DVH: dose-volume histograms; MLD: mean total lung dose; ROC: receiver operator characteristic.

\section{Authors' contributions}

J.Z., R.M.D., F-M.K. designed the research. J.Z., R.M.D., J-Y.J., H.W., C.F., L.Q., S.W., L.Y., M.K, M.M., and F-M.K performed data acquisition and analysis. J.Z., R.M.D., and F-M.K. wrote the paper, all authors provided reviewing comments and approved the final version.

\section{ACKNOWLEDGMENTS}

One or more of the authors are employees of the U.S. Government and this manuscript was prepared as part of their official duties. Title 17 U.S.C. $\$ 105$ provides that 'Copyright protection under this title is not available for any work of the United States Government.' Title 17 U.S.C $\$ 101$ defined a U.S. Government work as a work prepared by a military service member or employees of the U.S. Government as part of that person's official duties. The views in this article are those of the authors and do not necessarily reflect the views, official policy, or position of the Uniformed Services University of the Health Sciences, the Armed Forces Radiobiology Research Institute, Department of the Navy, Department of Defense or the U.S. Federal Government.

\section{CONFLICTS OF INTEREST}

Dr. Matuszak reports grants from NIH, during the conduct of the study; grants from Varian Medical Systems, personal fees from Pediatric Proton Consortium RegistryAdvisory Board, grants from NIH, outside the submitted work.

Dr. Kong's reports Travel Support and Speaker's Honorarium from Varian Medical System and Grants from $\mathrm{NIH} / \mathrm{NCI}$.

Other authors have no potential conflicts of interest to disclose.

\section{FUNDING}

This work was supported in part by NIH/NCI R01CA142840 (Kong). 


\section{REFERENCES}

1. Runowicz CD, Leach CR, Henry NL, Henry KS, Mackey HT, Cowens-Alvarado RL, Cannady RS, Pratt-Chapman ML, Edge SB, Jacobs LA, Hurria A, Marks LB, LaMonte $\mathrm{SJ}$, et al. American Cancer Society/American Society of Clinical Oncology Breast Cancer Survivorship Care Guideline. J Clin Oncol. 2016; 34:611-35.

2. García-Campelo R, Bernabé R, Cobo M, Corral J, Coves J, Dómine M, Nadal E, Rodriguez-Abreu D, Viñolas N, Massuti B. SEOM clinical guidelines for the treatment of non-small cell lung cancer (NSCLC) 2015. Clin Transl Oncol. 2015; 17:1020-29.

3. Wisnivesky JP, Halm E, Bonomi M, Powell C, Bagiella E. Effectiveness of radiation therapy for elderly patients with unresected stage I and II non-small cell lung cancer. Am J Respir Crit Care Med. 2010; 181:264-69.

4. Sandler HM, Curran WJ Jr, Turrisi AT 3rd. The influence of tumor size and pre-treatment staging on outcome following radiation therapy alone for stage I non-small cell lung cancer. Int J Radiat Oncol Biol Phys. 1990; 19:9-13.

5. Pignon JP, Arriagada R, Ihde DC, Johnson DH, Perry MC, Souhami RL, Brodin O, Joss RA, Kies MS, Lebeau B, Onoshi T, Østerlind K, Tattersall MH, Wagner H. A metaanalysis of thoracic radiotherapy for small-cell lung cancer. N Engl J Med. 1992; 327:1618-24.

6. Yamoah K, Showalter TN, Ohri N. Radiation Therapy Intensification for Solid Tumors: A Systematic Review of Randomized Trials. Int J Radiat Oncol Biol Phys. 2015; 93:737-45.

7. Schild SE, Vokes EE. Pathways to improving combined modality therapy for stage III non-small cell lung cancer. Ann Oncol. 2016; 27:590-99.

8. Bazan JG, White JR. The Role of Postmastectomy Radiation Therapy in Patients With Breast Cancer Responding to Neoadjuvant Chemotherapy. Semin Radiat Oncol. 2016; 26:51-58.

9. Matuschek C, Boelke E, Budach W, Speer V, Bojar H, Audretsch W, Nestle K. New aspects regarding neoadjuvant radiochemotherapy in locally advanced noninflammatory breast cancer and predictive factors for a pathologic complete remission: IGCS-0016 Breast Cancer. Int J Gynecol Cancer. 2015 (Suppl 1); 25:1.

10. Simone CB 2nd, Burri SH, Heinzerling JH. Novel radiotherapy approaches for lung cancer: combining radiation therapy with targeted and immunotherapies. Transl Lung Cancer Res. 2015; 4:545-52.

11. Tchekmedyian N, Gray JE, Creelan BC, Chiappori AA, Beg AA, Soliman H, Perez BA, Antonia SJ. Propelling immunotherapy combinations into the clinic. Oncology (Williston Park). 2015; 29:990-1002.

12. Movsas B, Raffin TA, Epstein AH, Link CJ Jr. Pulmonary radiation injury. Chest. 1997; 111:1061-76.
13. Bentzen SM, Skoczylas JZ, Bernier J. Quantitative clinical radiobiology of early and late lung reactions. Int J Radiat Biol. 2000; 76:453-62.

14. Marks LB, Yu X, Vujaskovic Z, Small W Jr, Folz R, Anscher MS. Radiation-induced lung injury. Semin Radiat Oncol. 2003; 13:333-45.

15. Claude L, Pérol D, Ginestet C, Falchero L, Arpin D, Vincent M, Martel I, Hominal S, Cordier JF, Carrie C. A prospective study on radiation pneumonitis following conformal radiation therapy in non-small-cell lung cancer: clinical and dosimetric factors analysis. Radiother Oncol. 2004; $71: 175-81$.

16. Tong AN, Yan P, Yuan GH, Lv XY, Gong H, Zhao H, Wang YM. Advantages of CyberKnife for inoperable stage I peripheral non-small-cell lung cancer compared to threedimensional conformal radiotherapy. Mol Clin Oncol. 2015; 3:442-48.

17. Abdulla S, Salavati A, Saboury B, Basu S, Torigian DA, Alavi A. Quantitative assessment of global lung inflammation following radiation therapy using FDG PET/ CT: a pilot study. Eur J Nucl Med Mol Imaging. 2014; 41:350-56.

18. Rosiello RA, Merrill WW. Radiation-induced lung injury. Clin Chest Med. 1990; 11:65-71.

19. Coggle JE, Lambert BE, Moores SR. Radiation effects in the lung. Environ Health Perspect. 1986; 70:261-91.

20. Emami B, Lyman J, Brown A, Coia L, Goitein M, Munzenrider JE, Shank B, Solin LJ, Wesson M. Tolerance of normal tissue to therapeutic irradiation. Int J Radiat Oncol Biol Phys. 1991; 21:109-22.

21. Siva S, MacManus M, Kron $T$, Best N, Smith J, Lobachevsky P, Ball D, Martin O. A pattern of early radiation-induced inflammatory cytokine expression is associated with lung toxicity in patients with non-small cell lung cancer. PLoS One. 2014; 9:e109560.

22. Vujaskovic Z, Marks LB, Anscher MS. The physical parameters and molecular events associated with radiationinduced lung toxicity. Semin Radiat Oncol. 2000; 10:296-307.

23. Chernecky C, Sarna L. Pulmonary toxicities of cancer therapy. Crit Care Nurs Clin North Am. 2000; 12:281-95.

24. Hughes-Davies L, Tarbell NJ, Coleman CN, Silver B, Shulman LN, Linggood R, Canellos GP, Mauch PM. Stage IA-IIB Hodgkin's disease: management and outcome of extensive thoracic involvement. Int J Radiat Oncol Biol Phys. 1997; 39:361-69.

25. Robnett TJ, Machtay M, Vines EF, McKenna MG, Algazy KM, McKenna WG. Factors predicting severe radiation pneumonitis in patients receiving definitive chemoradiation for lung cancer. Int J Radiat Oncol Biol Phys. 2000; 48:89-94.

26. Ghafoori P, Marks LB, Vujaskovic Z, Kelsey CR. Radiation-induced lung injury. Assessment, management, and prevention. Oncology. 2008; 22:37-47; discussion $52-33$. 
27. Abid SH, Malhotra V, Perry MC. Radiation-induced and chemotherapy-induced pulmonary injury. Curr Opin Oncol. 2001; 13:242-48.

28. Carlson K, Bäcklund L, Smedmyr B, Oberg G, Simonsson B. Pulmonary function and complications subsequent to autologous bone marrow transplantation. Bone Marrow Transplant. 1994; 14:805-11.

29. Sampath S, Schultheiss TE, Wong J. Dose response and factors related to interstitial pneumonitis after bone marrow transplant. Int J Radiat Oncol Biol Phys. 2005; 63:876-84.

30. Bradley J, Movsas B. Radiation pneumonitis and esophagitis in thoracic irradiation. Cancer Treat Res. 2006; 128:43-64.

31. Fu XL, Huang H, Bentel G, Clough R, Jirtle RL, Kong FM, Marks LB, Anscher MS. Predicting the risk of symptomatic radiation-induced lung injury using both the physical and biologic parameters $\mathrm{V}(30)$ and transforming growth factor beta. Int J Radiat Oncol Biol Phys. 2001; 50:899-908.

32. Marks LB, Bentzen SM, Deasy JO, Kong FM, Bradley JD, Vogelius IS, El Naqa I, Hubbs JL, Lebesque JV, Timmerman RD, Martel MK, Jackson A. Radiation dose-volume effects in the lung. Int J Radiat Oncol Biol Phys. 2010 (Suppl); 76:S70-76.

33. Fukada J, Shigematsu N, Ohashi T, Shiraishi Y, Takeuchi H, Kawaguchi O, Kitagawa Y. Pericardial and pleural effusions after definitive radiotherapy for esophageal cancer. J Radiat Res (Tokyo). 2012; 53:447-53.

34. Kumekawa Y, Kaneko K, Ito H, Kurahashi T, Konishi K, Katagiri A, Yamamoto T, Kuwahara M, Kubota Y, Muramoto T, Mizutani Y, Imawari M. Late toxicity in complete response cases after definitive chemoradiotherapy for esophageal squamous cell carcinoma. J Gastroenterol. 2006; 41:425-32.

35. Medhora M, Gao F, Glisch C, Narayanan J, Sharma A, Harmann LM, Lawlor MW, Snyder LA, Fish BL, Down JD, Moulder JE, Strande JL, Jacobs ER. Whole-thorax irradiation induces hypoxic respiratory failure, pleural effusions and cardiac remodeling. J Radiat Res (Tokyo). 2015; 56:248-60.

36. Bachman AL, Macken K. Pleural effusions following supervoltage radiation for breast carcinoma. Radiology. 1959; 72:699-709.
37. AJCC Cancer Staging Manual: Springer-Verlag New York). 2010.

38. Mergo PJ, Helmberger T, Didovic J, Cernigliaro J, Ros PR, Staab EV. New formula for quantification of pleural effusions from computed tomography. J Thorac Imaging. 1999; 14:122-25.

39. Moy MP, Levsky JM, Berko NS, Godelman A, Jain VR, Haramati LB. A new, simple method for estimating pleural effusion size on CT scans. Chest. 2013; 143:1054-59.

40. Hazlinger M, Ctvrtlik F, Langova K, Herman M. Quantification of pleural effusion on CT by simple measurement. Biomed Pap Med Fac Univ Palacky Olomouc Czech Repub. 2014; 158:107-11.

41. Blackmore CC, Black WC, Dallas RV, Crow HC. Pleural fluid volume estimation: a chest radiograph prediction rule. Acad Radiol. 1996; 3:103-09.

42. Karkhanis VS, Joshi JM. Pleural effusion: diagnosis, treatment, and management. Open Access Emerg Med. 2012; 4:31-52.

43. DeBiasi E, Puchalski J. Pleural effusions as markers of mortality and disease severity: a state-of-the-art review. Curr Opin Pulm Med. 2016; 22:386-91.

44. Stathopoulos GT, Kalomenidis I. Malignant pleural effusion: tumor-host interactions unleashed. Am J Respir Crit Care Med. 2012; 186:487-92.

45. Lui MM, Fitzgerald DB, Lee YC. Phenotyping malignant pleural effusions. Curr Opin Pulm Med. 2016; 22:350-55.

46. American Thoracic Society. Management of malignant pleural effusions. Am J Respir Crit Care Med. 2000; 162:1987-2001.

47. Wojno KJ, Olson JL, Sherman ME. Cytopathology of pleural effusions after radiotherapy. Acta Cytol. 1994; $38: 1-8$.

48. Jackson IL, Xu PT, Nguyen G, Down JD, Johnson CS, Katz BP, Hadley CC, Vujaskovic Z. Characterization of the dose response relationship for lung injury following acute radiation exposure in three well-established murine strains: developing an interspecies bridge to link animal models with human lung. Health Phys. 2014; 106:48-55. 